\title{
Study on the Relation between Thermal Oxidation Kinetics of Raw Constant Viscosity Natural Rubber and Ageing Characteristics of Its Vulcanizate
}

\author{
Bei-long ZHANG ${ }^{\text {a, }}$, Hong-hai HUANG, Wei-yong DENG, Li DING, \\ Yong-zhou WANG and Ping-yue WANG
}

Agricultural Product Processing Research Institute, Chinese Academy of Tropical Agricultural Sciences, P. O. Box 318, Zhanjiang, 524001, Guangdong, P.R. China

agdzjlong2013@163.com

${ }^{*}$ Corresponding author

Keywords: Natural rubber, Constant viscosity natural rubber, Ageing, Kinetics

\begin{abstract}
Thermal oxidation kinetics of raw constant viscosity natural rubber (CVNR) prepared with fresh natural rubber (NR) latex containing several difference viscosity stabilizers was studied. The comparison with the ageing characteristics of hot oxygen (hot air), ozone and light oxygen (ultraviolet light) of vulcanizate of raw CVNR was also studied. The results show that the thermal oxidation activation energies of CVNR prepared with hydroxylamine hydrochloride, hydrazine hydrate, aniline or semicarbazide hydrochloride are higher, extraordinarily that of aniline. The thermal oxidation activation energy of CVNR prepared with hydroxylammonium sulphate was lower and also compared to that of the control. The oxidation kinetics of raw CVNR had good correlation with thermal oxidation ageing characteristics of vulcanizate of raw CVNR, and had no correlation with the ageing characteristics of ozone and light oxygen.
\end{abstract}

\section{Introduction}

The molecules of natural rubber (NR) can crosslink [1,2] during storage because there are aldehydes $[1,3]$ on molecular chain, which will make molecular weight change, causing initial plasticity $\left(\mathrm{P}_{0}\right)$ and Mooney viscosity increase and plasticity retention index (PRI) decrease. Mooney viscosity is an important indicator measuring the processing property of NR. The change of Mooney viscosity of NR during storage affects greatly the processing property of NR. NR with constant viscosity can simplify the production technology of products, and maintains consistent performance of products. Constant viscosity natural rubber (CVNR) is prepared by the method of adding viscosity stabilizer into NR latex. The viscosity stabilizer can react with aldehyde to reduce the activity of aldehyde, which will prevent rubber from hardening ${ }^{4}$ and maintain stability of Mooney viscosity. The CVNR with different Mooney viscosity is obtained through the addition of different viscosity stabilizer. For example, The CVNR with low Mooney viscosity can be obtained through adding hydroxylamine hydrochloride or hydroxylammonium sulphate. CVNR with medium Mooney viscosity can be obtained through adding aniline $(0.03 \mathrm{phr})$ or semicarbazide hydrochloride. The CVNR with medium Mooney viscosity can be obtained through adding aniline ( $0.03 \mathrm{phr}$ ) or semicarbazide hydrochloride. CVNR with high Mooney viscosity can be obtained through adding aniline ( $0.05 \mathrm{phr})$ or hydrazine hydrate [5].

The physical and chemical properties of NR will change with addition of viscosity stabilizer. The effects of different viscosity stabilizer on NR are different. Some viscosity stabilizers will improve aging property of NR and some will wreck that. The 
aging of NR products is affected by environmental factors during storage. There are some studies on effects of viscosity stabilizers on physical and chemical properties of NR $[6,10]$, however, no paper is available about the effects of viscosity stabilizers on oxidation kinetics, bromine oxygen and light oxygen properties of NR. Therefore, the research on thermal oxidation kinetics of NR and to compare the thermal oxidation kinetics with ageing characteristics of hot oxygen (hot air), bromine oxygen and light oxygen (ultraviolet light) of vulcanizate of raw CVNR is of significance importance.

\section{Experiment}

\section{Materials}

The fresh NR latex was provided by Mengpeng Farm in Yunnan Province, The of China.

The viscosity stabilizers were of chemical grade, and others were of industrial grade.

\section{Preparation of Test Piece}

Aqueous solution containing 5\% of hydroxylamine hydrochloride, hydroxyl -ammonium sulphate, and hydrazine hydrate or semicarbazide hydrochloride (the concentration of aniline aqueous solution being 2.5\%) was added into fresh NR latex and stirred thoroughly, and then coagulation agent was added. The time of coagulum maturation is 18 hours. Then the coagulum were processed through creping, size reduction and drying. The drying temperature was $120^{\circ} \mathrm{C}$, and the drying time was 4 hours.

\section{Preparation of Vulcanizate}

The test samples were prepared according to the following formulation (ACS1): NR, 100.0; sulfur, 3.5; zinc oxide, 6.0; stearic acid, 0.5; and 2-mercaptobenzothiazole, (MBT) 0.5.The stocks were compounded according to China National Standard GB/T 6038-2006 [11].The vulcanizate samples were prepared with a plate vulcanizing press $(50 \mathrm{t}, 400 \times 400 \mathrm{~mm})$ controlled by microcomputer. The curing temperature was set at $140{ }^{0} \mathrm{C}$.

\section{Test}

A Differential Scanning Calorimeter DSC-220 (Seiko Instruments Inc) was used. The temperature rising rate was $4,5,6,8$ and $10^{\circ} \mathrm{C} / \mathrm{min}$, respectively. The air flow rate (atmosphere) was $50 \mathrm{~mL} / \mathrm{min}$. An Instron Tester (INSTRON) was used according to China National Standard GB/T528-1998 [12]. The hot- air ageing of test sample was carried out in an electric heated air-blast oven at $140^{\circ} \mathrm{C} \times 24$ hours according to China National Standard GB/T 3512-2014 [13]. The bromine oxygen ageing of test sample was carried out at ozone aging box at $40^{\circ} \mathrm{C} \times 4$ huors according to China National Standard GB/T 13642-2015 [14]. The tensile frequency for test sample was $50 \mathrm{~Hz}$ and the elongation was $20 \%$. The volume fraction of ozone concentration was $(50 \pm 5) \times 10^{-8}$, and the gas flow rate was $12 \mathrm{~mm} / \mathrm{s}$. The ultraviolet light ageing test was carried out in an ultraviolet ageing box with UV-B lamp $\times 48 \mathrm{~h}$ according to China National Standard GB/T 16585-1996 [15].

Ageing coefficient is calculated with follow equation: ageing coefficient $=$ (tensile strength after ageing $\times$ elongation at break after ageing) / (tensile strength before ageing $\times$ elongation at break before ageing) 


\section{Results and Discussion}

\section{Thermal Oxidation Kinetics of CVNR}

NR will oxidize slowly in environment temperature, and the oxidation will become faster in hot air (hot oxygen) environment. The hot oxidation ageing resistance of natural rubber is closely relative to thermal oxidation kinetics. It is difficult to obtain oxidation data of NR at room temperature. The oxidation of NR can be accelerated in a shorter time through heating, and the oxidation temperature of NR during heating can be acknowledged. The information of oxidation of NR can be obtained through analysis of these data with thermal kinetics equation. Zhang Bei-long ${ }^{16}$ have conformed that the first exothermal peak of $\mathrm{NR}$ at $185 \sim 205^{\circ} \mathrm{C}$ in air atmosphere is the oxidation exothermal peak of NR. The temperature Tp of oxidation exothermal peak of CVNR was obtained according to the method 16, and the oxidation activation energy of CVNR was obtained according to the way 16 and 17 . The temperature $\mathrm{Tp}$ of oxidation exothermal peak and the oxidation activation energy of CVNR are list in Table 1. The thermal oxidation activation energy of the sample containing hydroxylammonium sulphate is lower than that of the control. The thermal oxidation activation energies of the samples containing hydroxylamine hydrochloride, hydrazine hydrate, semicarbazide hydrochloride or aniline are higher than that of the control, extraordinarily that of aniline. The thermal oxidation activation energies of the samples show that hydroxylamine hydrochloride, hydrazine hydrate, semicarbazide hydrochloride or aniline can improve thermal oxidation- resistance of NR, and hydroxylammonium sulphate will wreck thermal oxidation- resistance of NR.

Table 1 The temperature Tp of oxidation exothermal peak and the oxidation activation energy of CVNR

\begin{tabular}{|c|c|c|c|c|c|c|c|}
\hline \multirow{3}{*}{ viscosity stabilizer } & \multicolumn{5}{|c|}{ Heating rate $\left({ }^{0} \mathrm{C} / \mathrm{min}\right)$} & \multirow{3}{*}{$\begin{array}{l}\text { oxidation } \\
\text { activatio } \\
\mathrm{n} \text { energy } \\
(\mathrm{kJ} / \mathrm{mol})\end{array}$} & \multirow{3}{*}{$\begin{array}{l}\text { correlation } \\
\text { coefficient }\end{array}$} \\
\hline & 4 & 5 & 6 & 8 & 10 & & \\
\hline & \multicolumn{5}{|c|}{$\begin{array}{l}\text { the largest peak temperature of oxidation } \\
\text { exothermal peak } \quad \mathrm{T}_{\mathrm{p}} \quad\left({ }^{0} \mathrm{C}\right) \\
\end{array}$} & & \\
\hline control & 189.78 & & 193.74 & 200.22 & 204.16 & 105.7 & 0.9852 \\
\hline $\begin{array}{l}\text { hydroxylamine } \\
\text { hydrochloride }\end{array}$ & 191.62 & 193.21 & 195.87 & 200.25 & 206.06 & 108.0 & 0.9814 \\
\hline $\begin{array}{l}\text { hydroxylammoniu } \\
\text { m sulphate }\end{array}$ & 189.18 & & 191.11 & 199.10 & 202.57 & 102.7 & 0.9533 \\
\hline hydrazine hydrate & 194.43 & & 202.81 & 206.55 & 209.57 & 106.7 & 0.9977 \\
\hline aniline & 189.49 & 191.97 & 193.66 & 197.17 & 203.09 & 118.0 & 0.9788 \\
\hline $\begin{array}{l}\text { semicarbazide } \\
\text { hydrochloride }\end{array}$ & 189.18 & 193.24 & 194.75 & 201.28 & 203.62 & 106.5 & 0.9925 \\
\hline
\end{tabular}

Relation between Aging Property of Vulcanizate of CVNR and Thermal Oxidation Kinetics of Raw CVNR

Relation between Hot Oxygen (Hot Air) Ageing Property of Vulcanizate of CVNR and Thermal Oxidation Kinetics of Raw CVNR. The tensile strength and the elongation at break of vulcanizate of CVNR prepared with various viscosity stabilizers before and after hot oxygen (hot air) aging, the hot oxygen (hot air) ageing coefficients, and the thermal oxidation activation energies of raw CVNR are list in Table 2. 
Table 2 Properties of vulcanizate of CVNR before and after hot oxygen (hot air) aging

\begin{tabular}{|c|c|c|c|c|c|c|}
\hline \multirow[b]{2}{*}{ viscosity stabilizer } & \multicolumn{2}{|c|}{ before aging } & \multicolumn{2}{|c|}{ after aging } & \multirow[b]{2}{*}{$\begin{array}{l}\text { ageing } \\
\text { coefficient }\end{array}$} & \multirow{2}{*}{$\begin{array}{c}\text { oxidation } \\
\text { activation } \\
\text { energy } \\
(\mathrm{kJ} / \mathrm{mol})\end{array}$} \\
\hline & $\begin{array}{l}\text { tensile } \\
\text { strength } \\
/ \mathrm{MPa} \\
\end{array}$ & $\begin{array}{l}\text { elongation } \\
\text { at break/\% }\end{array}$ & $\begin{array}{l}\text { tensile } \\
\text { strength } \\
/ \mathrm{MPa} \\
\end{array}$ & $\begin{array}{c}\text { elongation at } \\
\text { break/\% }\end{array}$ & & \\
\hline control & 22.8 & 760 & 15.6 & 628 & 0.57 & 105.7 \\
\hline $\begin{array}{l}\text { hydroxylahydmine } \\
\text { rochloride }\end{array}$ & 19.6 & 796 & 16.8 & 688 & 0.74 & 108.0 \\
\hline $\begin{array}{l}\text { hydroxylammonium } \\
\text { sulphate }\end{array}$ & 20.1 & 822 & 13.2 & 608 & 0.49 & 102.7 \\
\hline hydrazine hydrate & 21.5 & 786 & 18.3 & 658 & 0.71 & 106.7 \\
\hline aniline & 22.5 & 804 & 17.5 & 660 & 0.64 & 118.0 \\
\hline $\begin{array}{l}\text { semicarbazide } \\
\text { hydrochloride }\end{array}$ & 22.4 & 813 & 14.1 & 628 & 0.49 & 106.5 \\
\hline
\end{tabular}

It can be seen from the data in Table 2 that the tensile strength and the elongation at break of vulcanizate of CVNR prepared with hydroxylamine hydrochloride after hot oxygen ageing are higher than that of the control, and the hot oxygen ageing coefficient is obvious higher than that of the control. Meanwhile, the thermal oxidation activation energy of raw CVNR is also higher than that of the control. It is showed that the thermal oxidation activation energy of raw CVNR is relative to the hot oxygen ageing coefficient of vulcanizate of CVNR, and that hydroxylamine hydrochloride can improve the thermal oxidation- resistance of NR.

The tensile strength and the elongation at break of vulcanizate of CVNR prepared with hydroxylammonium sulphate after hot oxygen aging are lower than that of the control, and the hot oxygen ageing coefficient is obvious lower than that of the control. Meanwhile, the thermal oxidation activation energy of raw CVNR is also lower than that of the control. It is showed that the thermal oxidation activation energy of raw CVNR is relative to the hot oxygen ageing coefficient of vulcanizate of CVNR, and that hydroxylammonium sulphate can wreck the thermal oxidation- resistance of NR.

The tensile strength and the elongation at break of vulcanizate of CVNR prepared with hydrazine hydrate after hot oxygen ageing are higher than that of the control, and the hot oxygen ageing coefficient is obvious higher than that of the control. Meanwhile, the thermal oxidation activation energy of raw CVNR is also higher than that of the control. It is showed that the thermal oxidation activation energy of raw CVNR is relative to the hot oxygen ageing coefficient of vulcanizate of NR, and that hydroxylamine hydrochloride can improve the thermal oxidation- resistance of NR.

The tensile strength and the elongation at break of vulcanizate of CVNR prepared with aniline after hot oxygen ageing are higher than that of the control, and the ageing coefficient is also higher than that of the control. Meanwhile, the thermal oxidation activation energy of raw CVNR is obvious higher than that of the control. It is showed that the thermal oxidation activation energy of raw CVNR is relative to the hot oxygen ageing coefficient of vulcanizate of CVNR, and that hydroxylamine hydrochloride can improve the thermal activation- resistance of NR.

The tensile strength of vulcanizate of CVNR prepared with semicarbazide hydrochloride before hot oxygen ageing is very close to that of the control, and the 
elongation before hot oxygen ageing is obvious larger than that of the control. The tensile strength after ageing decreases obvious, comparing to that of the control. The hot oxygen ageing coefficient is lower than that of the control, but the thermal oxidation activation energy of raw CVNR is higher than that of the control. Semicarbazide hydrochloride brings about a harmful effect on the thermal oxidationresistance of NR. The thermal oxidation activation energy is not relative to the hot oxygen ageing coefficient of vulcanizate of CVNR prepared with semicarbazide hydrochloride, and the reason is perhaps the experimental error.

Relation between Ozone Ageing Property of Vulcanizate of CVNR and Thermal Oxidation Kinetics of Raw CVNR. The tensile strength and the elongation at break of vulcanizate of CVNR prepared with various viscosity stabilizers before and after ozone ageing, the ozone aging coefficients, and the thermal oxidation activation energies of raw CVNR are list in Table3.

It can be seen from data in Table 3 that the tensile strength and the ageing coefficient of CVNR prepared with hydroxylamine hydrochloride after ozone ageing obvious decrease, comparing to that of the control. Meanwhile, the elongation at break is also decrease. The data show that hydroxylamine hydrochloride wreck ozone ageing-resistance of NR.

The tensile strength and the elongation at break of CVNR prepared with hydroxylammonium sulphate after ozone ageing are decrease, but the decline is not very large comparing to that of the control, and the ozone ageing coefficient is higher than that of the control. It means that hydroxylammonium sulphate can improve ozone aging-resistance of NR.

Table 3 Properties of vulcanizate of CVNR before and after ozone ageing

\begin{tabular}{|c|c|c|c|c|c|c|}
\hline \multirow[b]{2}{*}{ viscosity stabilizer } & \multicolumn{2}{|c|}{ before ageing } & \multicolumn{2}{|c|}{ after ageing } & \multirow[b]{2}{*}{$\begin{array}{l}\text { ageing } \\
\text { coefficient }\end{array}$} & \multirow{2}{*}{$\begin{array}{c}\text { oxidation } \\
\text { activation } \\
\text { energy } \\
(\mathrm{kJ} / \mathrm{mol})\end{array}$} \\
\hline & $\begin{array}{l}\text { tensile } \\
\text { strength } \\
/ \mathrm{MPa}\end{array}$ & $\begin{array}{l}\text { elongation } \\
\text { at break/\% }\end{array}$ & $\begin{array}{l}\text { tensile } \\
\text { strengt } \\
\mathrm{h} \\
\text { /MPa }\end{array}$ & $\begin{array}{c}\text { elongation at } \\
\text { break/\% }\end{array}$ & & \\
\hline control & 22.8 & 760 & 19.9 & 760 & 0.87 & 105.7 \\
\hline $\begin{array}{l}\text { hydroxylahydmine } \\
\text { rochloride }\end{array}$ & 19.6 & 796 & 14.4 & 772 & 0.71 & 108.0 \\
\hline $\begin{array}{l}\text { hydroxylammoniu } \\
\text { m sulphate }\end{array}$ & 20.1 & 822 & 19.4 & 758 & 0.89 & 102.7 \\
\hline hydrazine hydrate & 21.5 & 786 & 14.1 & 734 & 0.61 & 106.7 \\
\hline aniline & 22.5 & 804 & 14.6 & 752 & 0.61 & 118.0 \\
\hline $\begin{array}{l}\text { semicarbazide } \\
\text { hydrochloride }\end{array}$ & 22.4 & 813 & 15.2 & 728 & 0.61 & 106.5 \\
\hline
\end{tabular}

The tensile strength and the elongation at break of CVNR prepared with hydrazine hydrate, aniline or semicarbazide hydrochloride are obvious decrease after ozone ageing, and the ozone ageing coefficients are obvious lower than that of the control. It means that hydrazine hydrate, aniline and semicarbazide hydrochloride can wreck ozone ageing-resistance of NR.

It is seen from data in Table 3 that the thermal oxidation activation energy of raw CVNR prepared with hydroxylammonium sulphate is among the lowest, and its ozone 
ageing coefficient is the largest. The thermal oxidation activation energy of the control is larger than that of raw CVNR prepared with hydroxylammonium sulphate and lower than that of raw CVNR prepared with hydroxylamine hydrochloride, hydrazine hydrate, aniline or semicarbazide hydrochloride, but its ozone ageing coefficient is lower than that of hydroxylammonium sulphate and larger than that of hydroxylamine hydrochloride, hydrazine hydrate, aniline or semicarbazide hydrochloride. The thermal oxidation activation energy of raw CVNR prepared with aniline is obvious larger than that of hydrazine hydrate or semicarbazide hydrochloride, but its ozone ageing coefficient is as the same as that of hydrazine hydrate or semicarbazide hydrochloride. It is showed that the thermal oxidation activation energy has no relative to the ozone ageing coefficient, and the thermal oxidation activation energy of raw NR can not reflect the ozone ageing- resistance of NR vulcanizate.

Relation between Ultraviolet Light Aging Property of Vulcanizate of Cvnr and Thermal Oxidation Kinetics of Raw Cvnr. The tensile strength and the elongation at break of vulcanizate of CVNR prepared with various viscosity stabilizers before and after ultraviolet light ageing, the ultraviolet light ageing coefficients and the thermal oxidation activation energies of raw CVNR are list in Table 4.

Table 4 Properties of vulcanizate of CVNR before and after ultraviolet light ageing

\begin{tabular}{|c|c|c|c|c|c|c|}
\hline \multirow[b]{2}{*}{ viscosity stabilizer } & \multicolumn{2}{|c|}{ before ageing } & \multicolumn{2}{|c|}{ after ageing } & \multirow{2}{*}{$\begin{array}{c}\text { ageing } \\
\text { coefficien } \\
\mathrm{t}\end{array}$} & \multirow{2}{*}{$\begin{array}{c}\text { oxidation } \\
\text { activation } \\
\text { energy } \\
(\mathrm{kJ} / \mathrm{mol})\end{array}$} \\
\hline & $\begin{array}{l}\text { tensile } \\
\text { strength } \\
/ \mathrm{MPa}\end{array}$ & $\begin{array}{c}\text { elongation at } \\
\text { break } / \%\end{array}$ & $\begin{array}{l}\text { tensile } \\
\text { strength } \\
/ \mathrm{MPa}\end{array}$ & $\begin{array}{c}\text { elongation at } \\
\text { break/\% }\end{array}$ & & \\
\hline control & 22.8 & 760 & 21.4 & 726 & 0.90 & 105.7 \\
\hline $\begin{array}{l}\text { hydroxylahydmine } \\
\text { rochloride }\end{array}$ & 19.6 & 796 & 17.2 & 714 & 0.79 & 108.0 \\
\hline $\begin{array}{l}\text { hydroxylammoniu } \\
\text { m sulphate }\end{array}$ & 20.1 & 822 & 19.6 & 714 & 0.85 & 102.7 \\
\hline hydrazine hydrate & 21.5 & 786 & 17.4 & 712 & 0.73 & 106.7 \\
\hline aniline & 22.5 & 804 & 19.1 & 747 & 0.79 & 118.0 \\
\hline $\begin{array}{l}\text { semicarbazide } \\
\text { hydrochloride }\end{array}$ & 22.4 & 813 & 18.5 & 706 & 0.81 & 106.5 \\
\hline
\end{tabular}

The data in Table 4 show that the tensile strength and the elongation at break of the vulcanizate of CVNR prepared with various viscosity stabilizers after ultraviolet light ageing are obvious decrease, and the ultraviolet light aging coefficients are lower than that of the control. It can be seen from the ultraviolet light ageing coefficients that ultraviolet light aging-resistance of vulcanizate of CVNR prepared with hydroxylammonium sulphate is relatively better than that of other viscosity stabilizers because its ultraviolet light ageing coefficient is the largest among all viscosity stabilizers. The ultraviolet light aging-resistance of vulcanizate of CVNR prepared with hydrazine hydrate is the worst as its ultraviolet light ageing coefficient is the smallest among all viscosity stabilizers. The ultraviolet light ageing-resistance of vulcanizate of CVNR prepared with semicarbazide hydrochloride is better than that of hydroxylamine hydrochloride and aniline. The ultraviolet light ageing-resistance of vulcanizate of CVNR prepared with hydroxylamine hydrochloride is as the same as that of aniline because their ultraviolet light ageing coefficients are the same. There is no any regular relation between ultraviolet light ageing coefficients and oxidation activation energies, comparing ultraviolet light ageing coefficients of vulcanizate with 
oxidation activation energies of raw rubber. Therefore the thermal oxidation activation energy can not be used for characterization of the ultraviolet light ageing-resistance of vulcanizate.

\section{Conclusions}

The thermal oxidation activation energy of raw CVNR is close relative to the thermal oxygen (hot air) ageing coefficient and can reflect the thermal oxygen (hot air) aging characteristics of vulcanizate. The thermal oxidation activation energy of raw CVNR has no relation to the ozone ageing coefficient and the ultraviolet light ageing coefficient, and can not be used for characterization of the ozone ageing property and the ultraviolet light ageing properties of vulcanizate.

\section{Acknowledgement}

This research was financially supported by the provincial science and technology planning project of Guangdong (No.2015A020209012)

\section{References}

[1] Sekhar, B.C,. Journal of polymer science, 1960, 48(150): 133-137.

[2] Li Pei-sen, Li Xiao-xia, Chen cheng-hai,. Chinese Journal of Tropical Crops., 1988, 9(1): 73-82

[3] Li Pei-sen., China Tropical Crops Processing, 1985, (4): 10-16

[4] Sekhar, B.C, Rubber chemistry and technology, 1962, 35: 889-895

[5] Huang Hong-hai, Zhang Bei-long, Deng Wei-yong., Chinese Journal of Tropical Agriculture, 2010, 30(3): 1-5

[6] Chin P.S., Rubb.Res.Inst.Malaya., 1969, 22(1), 56.

[7] Gan S.N., Journal of Macromolecular Science-pure and Applied Chemistry., 1996, 33(12): 1939

[8] Liu Hui-lun, Zhang Bei-long, Deng Wei-yong, China Rubber Industry, 1999, 46(2): 78

[9] Huang Ke-feng, China Tropical Agriculture Engineering, 2000, (2): 15

[10]Li Zhi-jun, Zao Yan-fang, Liao Jian-he, China Elastomer., 2002, 12(5): 10

[11]GB/T 6038-2006 Rubber test mixes-Preparation, mixing and vulcanization-Equipment and procedures

[12] GB/T 528-2009 Rubber, vulcanized or thermoplastic - Determination of tensile stress-strain properties

[13] GB/T 3512-2014 Rubber, vulcanized or thermoplastic-Accelerated ageing and heat resistance tests

[14]GB/T 13642-2015 Rubber, vulcanized or thermoplastic - Resistance to ozone cracking-Dynamic strain testing

[15]GB/T 16585-1996 Rubber vulcanized-Test method of resistance to artificial weathering (Fluorescent UV lamp) 
[16]Bei-long Zhang, Wei-Yong Deng, et.al, J.Appl.Polym.Sci., 2006, 100: 4113-4119

[17]Lye P H, Toh H K., J.Appl.Polym.Sci., 1984, 29: 2628 